\title{
Application of Sequential Indicator Simulation in Geological Study of X Oilfield in Zhujiangkou Basin
}

\author{
Linlin Wang1, Yongbiao Wang ${ }^{2 *}$ \\ ${ }^{1}$ Petroleum Exploration \& Production Research Institute, SINOPEC, Beijing, China \\ ${ }^{2}$ Research Institute of Zhanjiang Branch, CNOOC Co. Ltd., Zhanjiang, China \\ Email: wanglinlin.syky@sinopec.com, *yongbiao_cnooc@126.com
}

How to cite this paper: Wang, L.L. and Wang, Y.B. (2020) Application of Sequential Indicator Simulation in Geological Study of X Oilfield in Zhujiangkou Basin. Open Journal of Yangtze Gas and Oil, 5, 16-25. https://doi.org/10.4236/ojogas.2020.51002

Received: December 16, 2019

Accepted: January 11, 2020

Published: January 14, 2020

Copyright $\odot 2020$ by author(s) and Scientific Research Publishing Inc. This work is licensed under the Creative Commons Attribution International License (CC BY 4.0).

http://creativecommons.org/licenses/by/4.0/ (c) (i) Open Access

\begin{abstract}
Sequential indicator simulation is a commonly used method for discrete variable simulation in 3D geological modeling and a widely used stochastic simulation method, which can be used not only for continuous variable simulation but also for discrete variable simulation. In this paper, the X Oilfield in the western South China Sea is taken as an example to compare the sequential indicator simulation method and the Indicator Kriging interpolation method. The results of the final comparison show that the results of the lithofacies model established by the Indicator Kriging deterministic interpolation method are overly smooth, and its coincidence rate with the geological statistical results is not high, thus cannot well reflect the heterogeneity of the underground reservoir, while the simulation results of the lithofacies model established by the sequential indicator stochastic simulation method can fit well with the statistical law of the well, which has eliminated the smoothing effect of Kriging interpolation, thus can better reflect the heterogeneity of the underground reservoir. Therefore, the sequential indicator simulation is more suitable for the characterization of sand bodies and the study of reservoir heterogeneity.
\end{abstract}

\section{Keywords}

3D Geological Modeling, Sequential Indicator, Indicator Kriging, Lithofacies, Heterogeneity, Smoothing Effect

\section{Introduction}

The Zhuhai Formation of X Oilfield in Zhujiangkou Basin belongs to fan delta front sedimentary environment, where estuarine dam, front sheet sand and dis- 
tal sand bar are developed, due to ocean wave modification. Fan-delta reservoir is one of the most common reservoirs in the study area. Modeling methods for sedimentary microfacies and lithofacies are now well developed, such as target-based method, sequential indicator simulation, and Indicator Kriging [1]-[6], but most of them focus on continental facies. In this paper, the sequential indicator simulation is used to describe the fan delta sand body in detail. The sequential indicator simulation has a widely used stochastic simulation method [7]-[11], which was first proposed by A. Journel. It can be used for stochastic simulation of discrete variables as well as continuous variables [12]. Without being constrained by the assumption of normal distribution, this method, instead, converts the conditional data into indication data through a series of thresholds based on the existing data and uses Indicator Kriging to estimate the local conditional probability distribution at each network point according to the indicator variation function of each discrete variable. The author applies this method to study the lithologic characteristics of reservoir in the Zhuhai Formation in the X Oilfield in the Zhujiangkou Basin and compare it with the Indicator Kriging method through detailed analysis.

\section{Principles of Sequential Indicator Simulation}

Before simulation calculation, the indicator transformation must be first carried out, that is, the process of encoding the original data into 0 and 1 according to different threshold values [13]. Assuming the parameter $Z(x)$ at $X$, the indicator transformation for the threshold value $Z c$ can be written as:

$$
I(u, z)= \begin{cases}1 & Z(u) \leq Z c \\ 0 & \text { Others }\end{cases}
$$

Then:

$$
\operatorname{Prob}\{I(u)=1 \mid(n)\}=E\{I(u) \mid(n)\}
$$

The indicator transformation can also be used to transform some qualitative or type variables, for example, if 1 represents the occurrence of sandstone, then 0 nonoccurrence (that is, the occurrence of other rock types). It can also be interpretation and inference of geologists. Therefore data of different kinds and accuracies can be transformed into 1 and 0 for data synthesis. The above formula is an equal weight indicator weighting method, but the unequal weighting method is also usually used for predicting the unknown:

$$
F(z ; x \mid(n))=[i(z ; x)]^{*}=\sum_{j=1}^{n} a_{j}(z ; x) \cdot i\left(z ; z_{j}\right)
$$

where, $a_{f}(Z, x)$ is the weight coefficient, which can be obtained by solving the following system of equation:

$$
\left\{\begin{array}{l}
\sum_{j=1}^{n} a_{j}(z ; x) \cdot C_{I}\left(z, x_{j^{\prime}}-X_{j^{\prime}}\right)+\mu(z ; x)=C_{I}\left(z, z_{j}\right), j=1, \cdots, n \\
\sum_{j^{\prime}=1}^{n} a_{j^{\prime}}(z ; x)=1
\end{array}\right.
$$


For a certain position, each threshold value corresponds to one such system of equations. In fact, within the range of variable variation, the range can be discretized with $K$ threshold values, $Z_{k}, k=1, \cdots, K$. Therefore, it is necessary to solve $K$ equation systems at each location to obtain the discrete cumulative function $F(z k, x q(n))$ so as to evaluate the uncertainty. The values of the cumulative density function between $\left[Z_{K}, Z_{K+1}\right]$ can be obtained by linear interpolation or other methods [13] [14].

Mainly based on this concept, the sequential indicator simulation is proposed, for which one of the essential question is how to be faithful to the spatial connectivity pattern of known data and information, so that the model can reflect the heterogeneity of parameters.

The greatest advantage of indicator simulation is to simulate complex anisotropic geological phenomena and extreme values of continuous distribution. For type variables (phases) with different continuous distributions, different variograms can be specified to create anisotropic simulated images.

The biggest difference between the Indicator Kriging method and the sequential Indicator Kriging method is that the latter establishes a random probability distribution model based on the number of the random seeds, while the former establishes a deterministic model according to the index with the highest selection expectation.

\section{Application Example}

\subsection{General Situation of Project Location}

The study area is located on the east side of the middle part of xx Depression in Zhujiangkou Basin. The Zhuhai Formation in the study area is a semi-anticlinal fault-nose structure controlled by the fault, with a near E-W strike, and the structure tilts north, east and south [15] [16]. The trap area of Zhuhai Formation is small, but its closing range is large. All faults in the oilfield are normal faults, with strikes mainly including near E-W strike, S-N strike, NEE-SWW strike and NW-SE strike (Figure 1).

During the sedimentation of Zhuhai Formation, the subaqueous distributary channel came from the southeast provenance, developed fan delta front to the northwest, and extended from the delta inner front controlled by river course to the delta outer front controlled by sea wave [17]. In general, due to the direct entry of the fan delta into the sea/bay, massive amounts of terrigenous debris are accumulating rapidly nearby. Therefore, the sedimentary sand body is well developed, and the sand body has a high space superposition rate. It can be found from the sedimentary facies of the study area that the interlayer is very well developed and the reservoir heterogeneity is strong during the well profile interpretation (Figure 2). Therefore, it is of great practical significance to establish a geological model which can well reflect the heterogeneity and lithologic characteristics of reservoirs for the analysis of the spatial distribution of sand bodies and the reservoir combination of the Zhuhai Formation in the study area. 


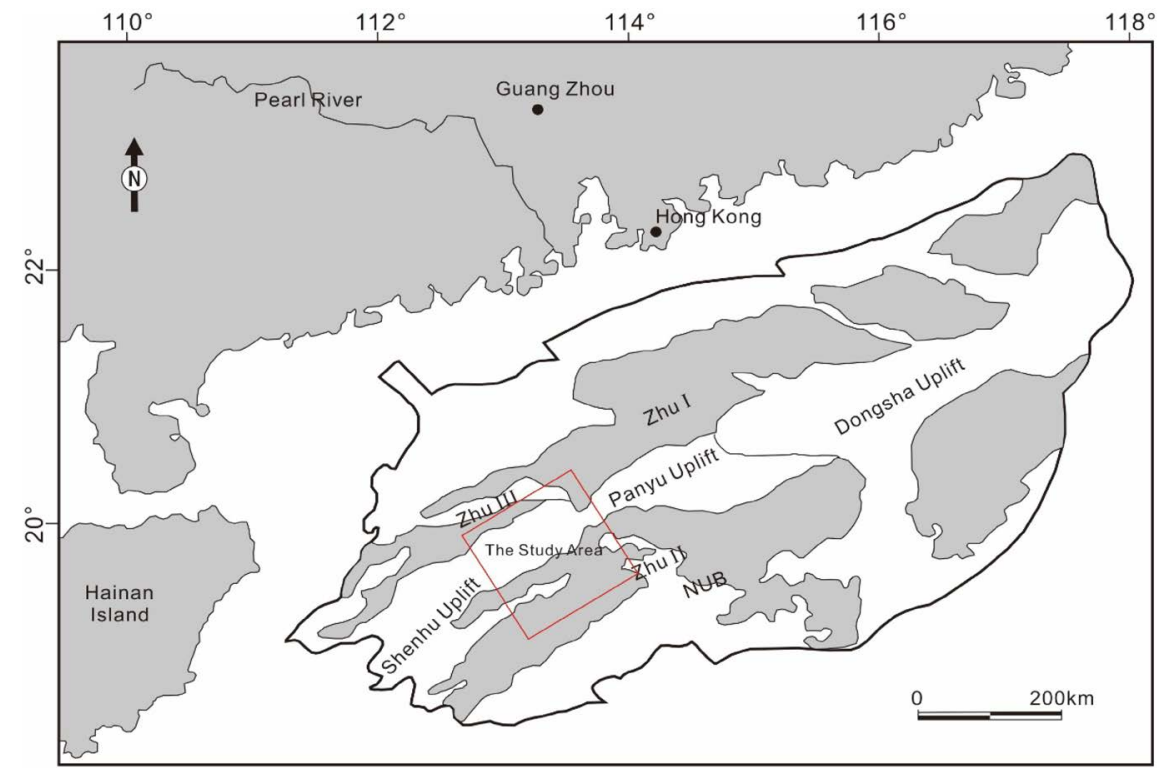

Figure 1. The tectonic elements of the Zhujiangkou Basin on the northern South China Sea and the specific location of the study area (according toJuang et al., 2003).

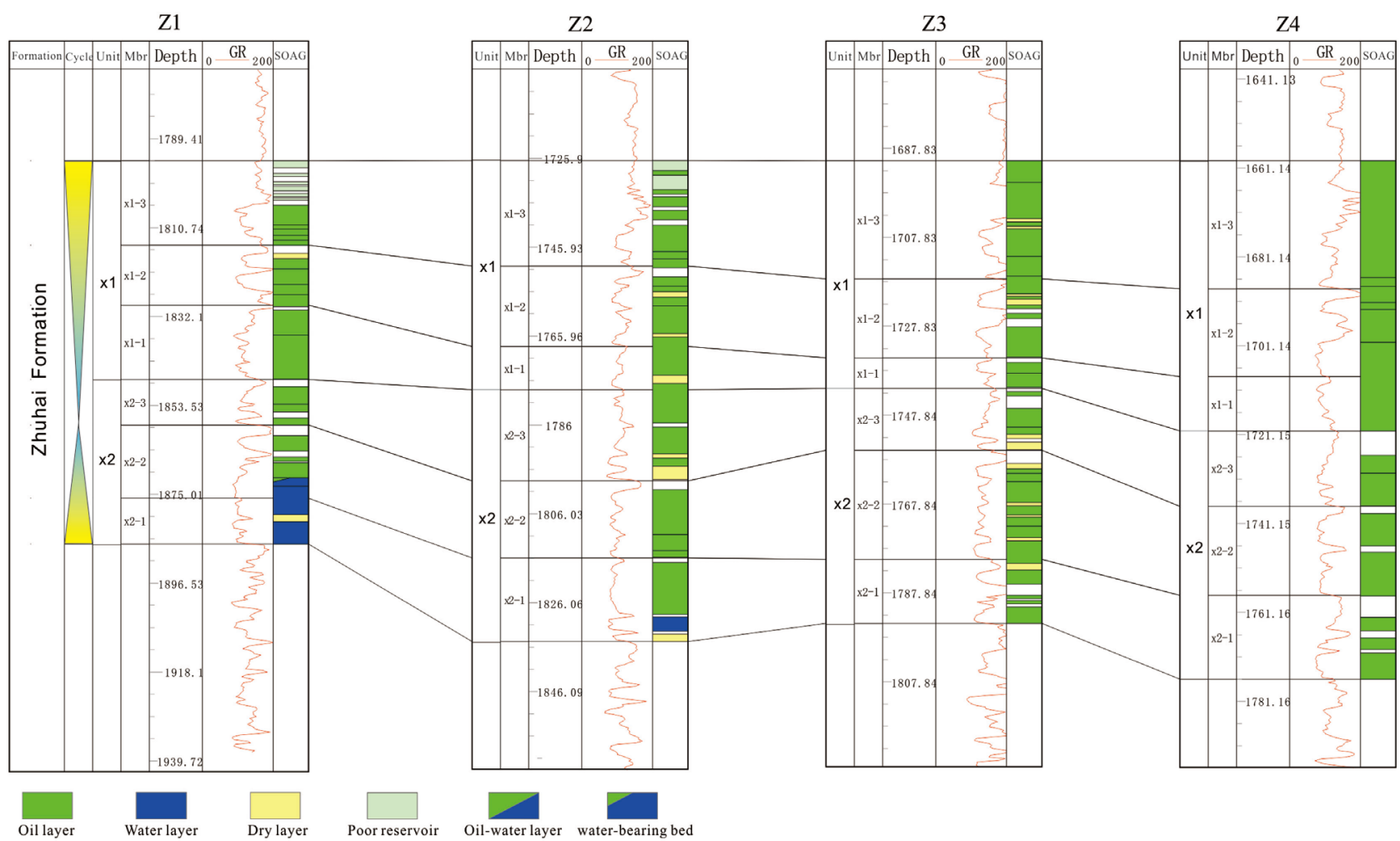

Figure 2. The well profile interpretation of Oil Group X of Zhuhai Formation.

\subsection{Modeling Process}

The model was created by software of Petrel 2016, and the key parameters of drilling stratification, lithology type, and sedimentary microfacies type were usedtobuild the model. The lithologic curve of these wells that participate in the simulation is the result of the standardization of the logging curve. As the litho- 
facies are mainly divided into sandstone and mudstone in interpretation results, and that sandstone is also divided into reservoir sandstone and dry layer, hierarchical simulation is used to depict lithofacies distribution in the simulation process. Firstly, the distribution of sandstone facies and mudstone facies is simulated, and then the distribution of reservoir sandstone and dry layers in sandstone facies is simulated. The fluid phase model established by sand mudstone facies constraint can well reveal the characteristics of plane distribution and vertical superposition rules of reservoir sandstone, dry layer and mudstone.

The variogram is the key to stochastic modeling [18]. Thereinto, the parameter variation is the parameter describing the spatial correlation state of the regionalized variable, whose size reflects the distance between the variables in spatial correlation, and further reflects the degree of heterogeneity of variables in different directions. The size of the variable range and the main direction will directly affect the results of the stochastic simulation, so it is necessary to analyze the variogram in detail before the simulation. Based on the sedimentary background and provenance direction of the study area, it can be get that the main direction of the variogram is SEE-NWW, with the main range of $900 \mathrm{~m}$, the second range of $600 \mathrm{~m}$ and the vertical range of $5 \mathrm{~m}$, and other structural characteristic parameters of the variogram through a detailed analysis on the variogram. Based on the variogram analysis, the relative content and thickness distribution of sand-mudstone facies on well point are counted, and their relative content and vertical variation rules on each small layer plane are restrained. Based on the above data analysis, the sequential indicator method is used to simulate the lithofacies distribution probability model (Figure 3 ). In the lithofacies model of sandstone facies, relative content and thickness distribution characteristics of reservoir sandstones and dry layer well point and the variogram under constraints of sandstone facies are analyzed. Then finally, the fluid phase model can be simulated using the sequential indicator method under the constraints of sand-mudstone facies. Similarly, the fluid phase model of Indicator Kriging interpolation using the established process is established, so as to lay a foundation for the simulation and comparative analysis of reservoir spatial distribution in the study area by these two models in the next step.

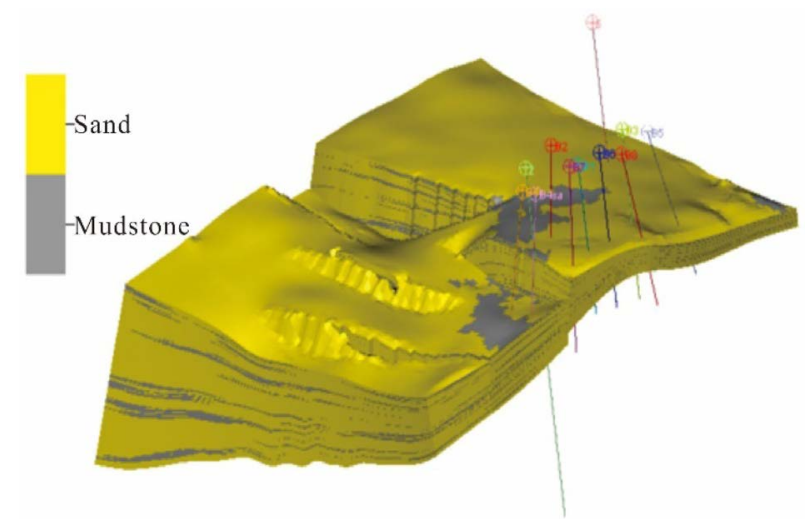

Figure 3. Sand-mudstone facies model of sequential indicator simulation. 


\subsection{Result Analysis}

As can be seen from the fluid phase models of the sequential indicator simulation and Indicator Kriging (Figure 4 and Figure 5): the results of Indicator Kriging interpolation shows an obvious smoothing effect, which ignores the random noise generated between wells, thus cannot well describe the heterogeneity of the underground reservoir; The results of sequential indicator simulation have eliminated the excessive smoothing effect, and the continuity of several lithologies is also good, thus they can fully depict the heterogeneity of underground reservoirs and the spatial distribution rules of lithofacies; The comparison of the lithofacies percentages of the model between sequential indicator simulation and Indicator Kriging interpolation shows that the result of sequential indicator simulation is closer to the percentage of lithofacies of well point statistics (Figure 6 and Figure 7). Whether the simulation results are consistent with the hard data of the well point is one of the most important indexes to test whether the model is reasonable or not; As also can be seen in Figure 7 and Figure 8 , not only the sequential indicator simulation method can better describe the uncertainty between wells, but also the mudstone interlayer that is simulated by its simulation results is more in line with the geological understanding in Figure 2; Generally speaking, when the number of well location is fewer, the sequential indicator simulation method is better than the Indicator Kriging interpolation in characterizing the reservoir, and also can better reflect the uncertainty of the underground reservoir.

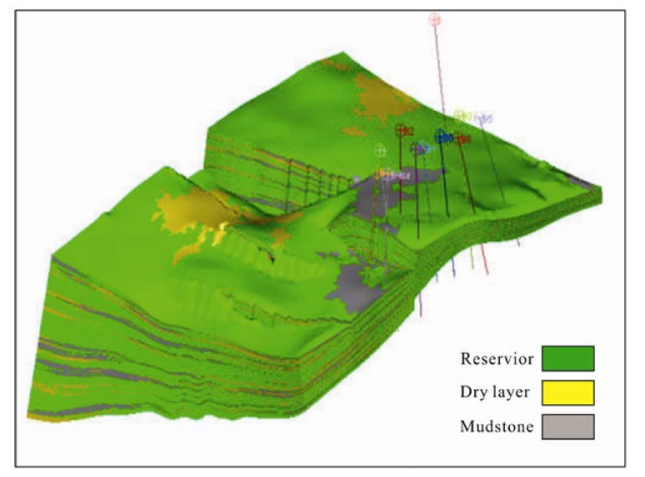

Figure 4. The results of fluid phase models of sequential indicator simulation.

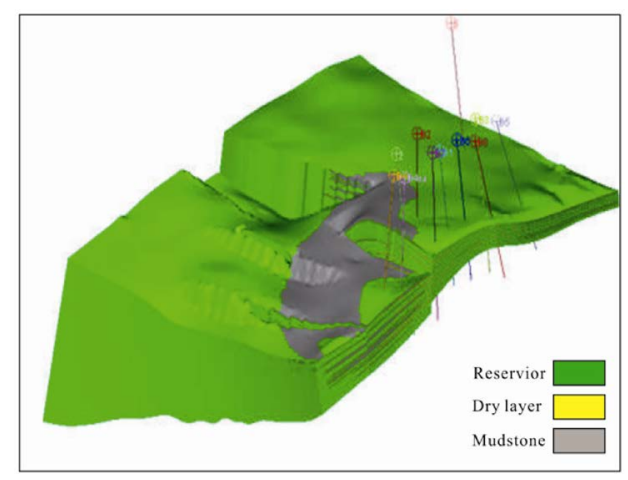

Figure 5. The results of fluid phase models of Indicator Kriging interpolation. 


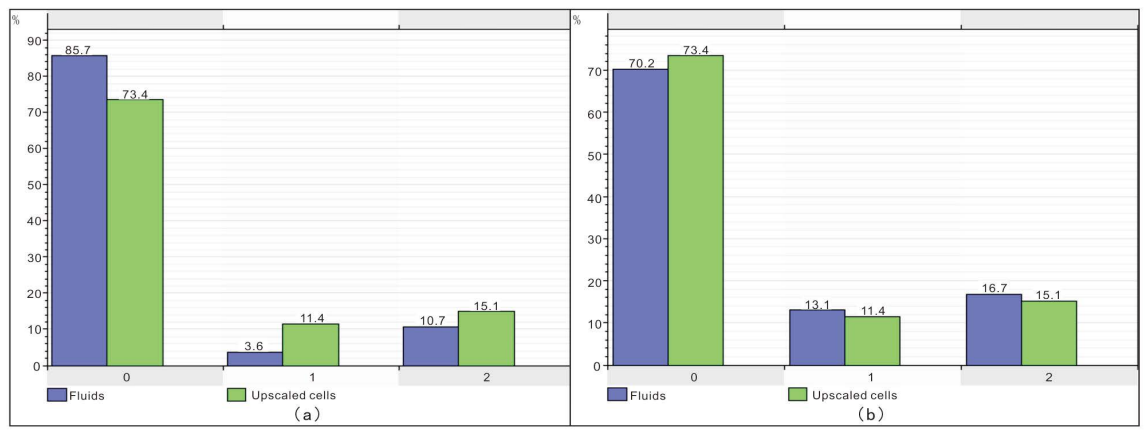

Figure 6. Comparison of lithofacies percentage contents of sequential indicator simulation and Indicator Kriging interpolation, (a) Lithofacies percentage content of sequential indicator simulation; (b) Lithofacies percentage content of Indicator Kriging interpolation.

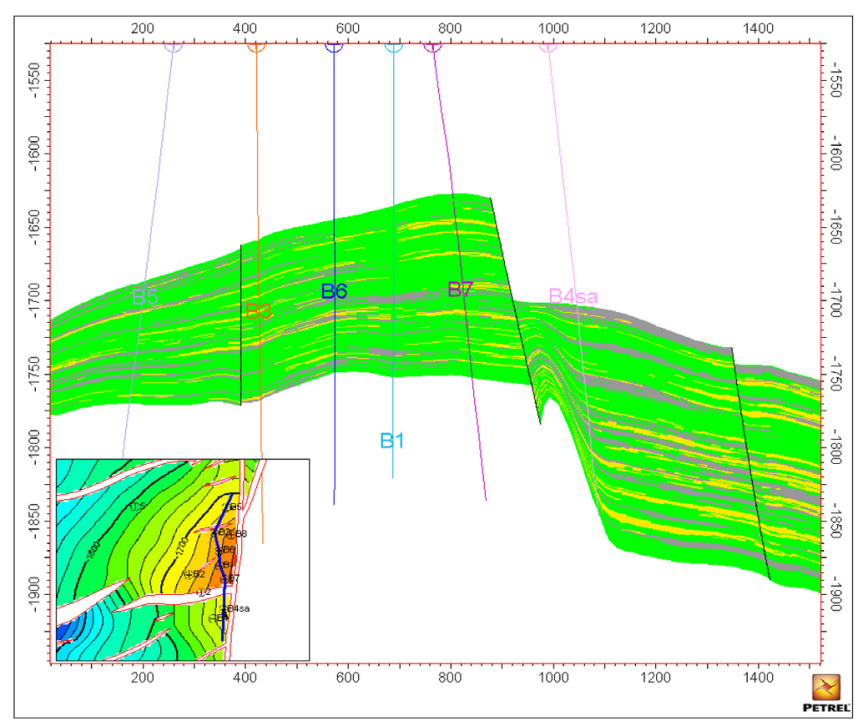

Figure 7. Cross-well profiles of fluid phase models of sequential indicator simulation.

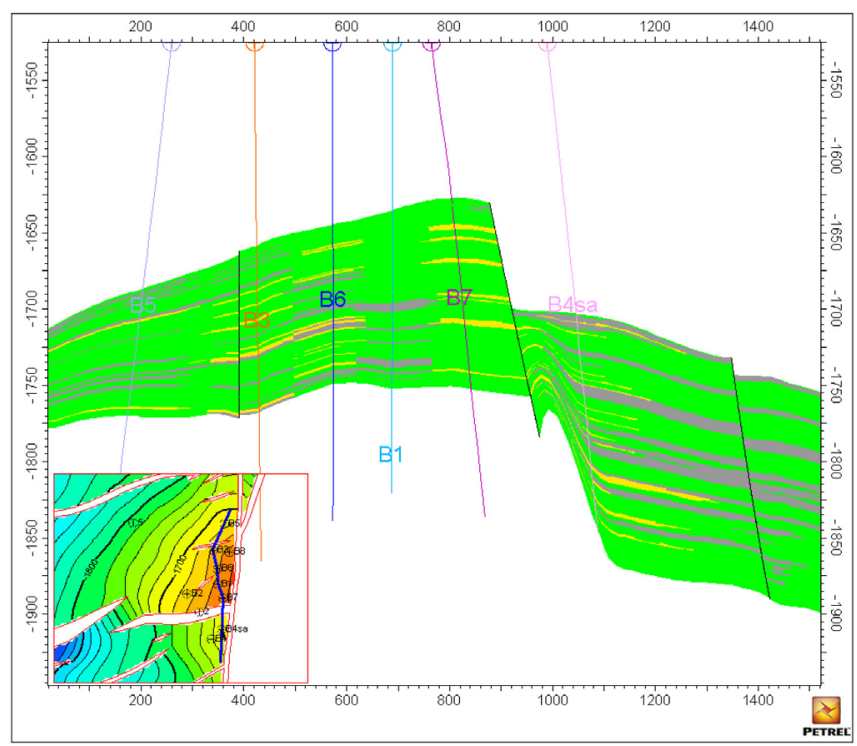

Figure 8. Cross-well profiles of fluid phase models of Indicator Kriging interpolation. 


\subsection{Model Testing}

Conventional geological model test methods include thinning testing, new well testing and dynamic verification, etc. [19] [20]. Thinning testing is used in this paper to test the model, due to limitations in conditions and data. After removing some of the drilled wells, the lithofacies of the study area are simulated under the condition that the original simulation parameters are not changed, and the petrographic data of removed well locations are extracted from the simulation results to compare with the petrographic data of known well locations.

Well Z2 is randomly removed from the wells in the study area, and then the lithofacies of the study area is simulated using sequential indicator simulation method [4] (Figure 9 and Figure 10). The figure shows the comparison of the thinning results with the original fluid phase results. As can be seen from the figure, there is little difference between the simulation results of Z2 well after thinning and those of the original fluid phase; In the original fluid facies simulation results, there are 23 mudstone facies grids, 14 dry layer facies grids, 163 reservoir facies grids in well $\mathrm{Z} 2$, while in the simulation results after thinning, there are 30 mudstone phase grids, 20 dry layer facies grids and 150 reservoir grids in well Z2, with a coincidence rate of over $80 \%$.

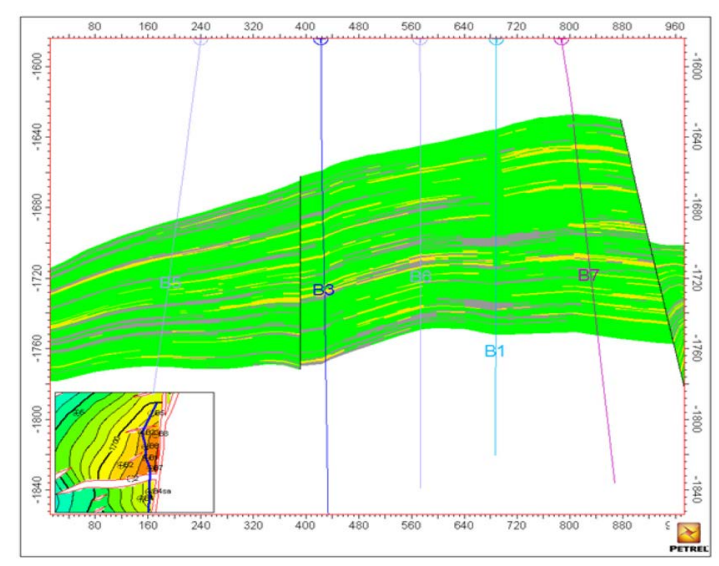

Figure 9. The results of sequential indicator simulation on $\mathrm{Z} 2$ well.

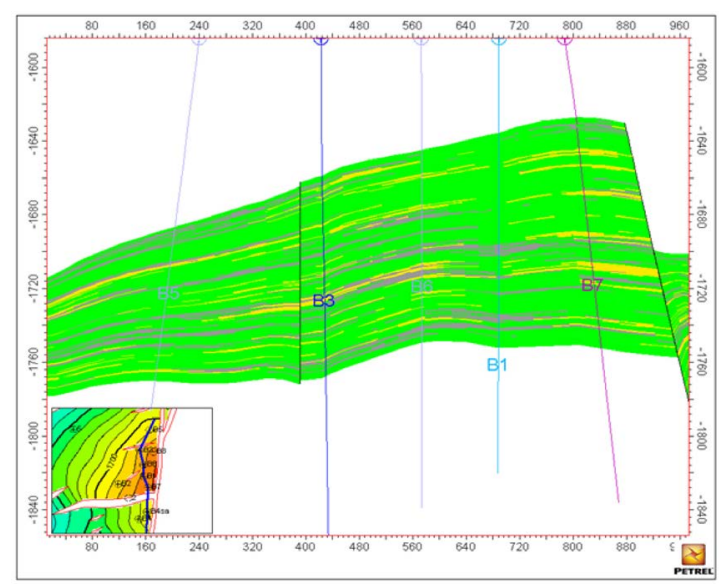

Figure 10. The results of original fluid phase results on $\mathrm{Z} 2$ well. 


\section{Conclusion}

According the comparison of the lithofacies models of the Zhuhai Formation of $\mathrm{X}$ Oilfield in Zhujiangkou Basin established by sequential indicator simulation and Indicator Kriging, it can be seen that the sequential indicator simulation can not only overcome the smoothing effect of the Indicator Kriging on the parameters, but can also reflect the slight changes in the parameters and characterize the uncertainty between the wells. The sequential indicator simulation method can better reflect the heterogeneity of fan-delta sand body and describe the spatial distribution of interlayer than the Indicator Kriging interpolation method.

\section{Conflicts of Interest}

The authors declare no conflicts of interest regarding the publication of this paper.

\section{References}

[1] Deutsch, C.V. and Wang, L. (1996) Hierarchical Object-Based Stochastic Modeling of Fluvial Reservoirs. Mathematical Geology, 28, 857-880. https://doi.org/10.1007/BF02066005

[2] Li, Y., Zhang, Z., Hu, W. and Xiong, P. (2011) Study on Facies-Controlled Water-Flooding Model for the First Member of Shahejie Formation in Pucheng Oilfield, Dongpu Depression. Fault-Block Oil \& Gas Field, 18, 505-507.

[3] Wu, X., Li, S., Yin, Y., Zhu, Y., Xu, Z. and Xiong, R. (2009) Application of Facies-Controlled Stochastic Modeling in Heterogeneity Study. Fault-Block Oil \& Gas Field, 16, 58-60.

[4] Feng, G.Q., Li, Y., Lin, Z.H. and Wang, Y.M. (2001) Application of Sequential Indicator Simulation Method to Delineating Sedimentary Microfacies. Journal of Southwest Petroleum Institute, 23, 1-4.

[5] Yin, Y., Feng, S. and Yin, T. (2012) Comparison Study on Modeling Method of Meandering River Reservoir. Fault-Block Oil \& Gas Field, 19, 44-46.

[6] Wang, Y.W., Zhang, J.M., Wang, M., Pan, B.Z., Xing, Y.J. and Shi, D.H. (2010) Simulation of Lithology and Porosity of Volcanic Rock Reservoir Based on Sequential Indicator Simulation. Journal of Jilin University, 40, 455-460.

[7] Vries, L.M.D., Carrera, J., Falivene, O., Gratacós, O. and Slooten, L.J. (2009) Application of Multiple Point Geostatistics to Non-Stationary Images. Mathematical Geosciences, 41, 29-42. https://doi.org/10.1007/s11004-008-9188-y

[8] Nunes, R. and Almeida, J. (2010) Parallelization of Sequential Gaussian, Indicator and Direct Simulation Algorithms. Computers \& Geosciences, 36, 1042-1052. https://doi.org/10.1016/j.cageo.2010.03.005

[9] Bastante, F.G., Ordóñez, C., Taboada, J. and Matías, J.M. (2008) Comparison of Indicator Kriging, Conditional Indicator Simulation and Multiple-Point Statistics Used to Model Slate Deposits. Engineering Geology, 98, 50-59. https://doi.org/10.1016/j.enggeo.2008.01.006

[10] Bu, F. and Zhang, Y. (2013) Modeling of High-Sinuosity Deep Water Turbidite Channel. Science \& Technology Review, 31, 70-73.

[11] Du, Q., Hou, J. and Lu, M. (1999) A Predictable Geologic Model of Sedimentary Facies and Sands. Acta Petrolei Sinica, 20, 45-50. 
[12] Journel, A.G., Gundeso, R., Gringarten, E. and Yao, T. (1998) Stochastic Modelling of a Fluvial Reservoir: A Comparative Review of Algorithms. Journal of Petroleum Science \& Engineering, 21, 95-121. https://doi.org/10.1016/S0920-4105(98)00044-8

[13] Journel, A.G. and Isaaks, E.H. (1984) Conditional Indicator Simulation: Application to a Saskatchewan Uranium Deposit. Journal of the International Association for Mathematical Geology, 16, 685-718. https://doi.org/10.1007/BF01033030

[14] Juang, K.W., Chen, Y.S. and Lee, D.Y. (2003) Using Sequential Indicator Simulation to Assess the Uncertainty of Delineating Heavy-Metal Contaminated Soils. Environmental Pollution, 127, 229-238. https://doi.org/10.1016/j.envpol.2003.07.001

[15] Jiang, H., Wang, H., Li. J., Chen, S., Lin, Z., Fang, X. and Cai, J. (2009) Analysis on Sequence Formation Styles of Zhu-3 Depression in Zhujiangkou Basin. Marine Geology \& Quaternary Geology, 29, 87-94. https://doi.org/10.3724/SP.J.1140.2009.01087

[16] Jiang, H., Wang, H., Xiao, J., Lin, Z., Lv, X. and Cai, J. (2008) Tectonic Inversion and Its Relationship with Hydrocarbon Accumulation in Zhu-3 Depression of Zhujiangkou Basin. Acta Petrolei Sinica, 29, 372-377. https://doi.org/10.3724/SP.J.1140.2009.01087

[17] Zhu, W., Li, M. and Wu, P. (1997) Petroleum System in Zhu-3 Depression of Zhujiangkou Basin. Petroleum Exploration \& Development, 24, 21-23.

[18] Wang, G.J., Zhao, L.M., Wei, L.I. and Zhao, G.L. (2005) Sensitivity of Variogram in Stochastic Modeling. Petroleum Exploration \& Development, 32, 72-75.

[19] Barabas, N., Goovaerts, P. and Adriaens, P. (2001) Geostatistical Assessment and Validation of Uncertainty for Three-Dimensional Dioxin Data from Sediments in an Estuarine River. Environmental Science \& Technology, 35, 3294-3301. https://doi.org/10.1021/es010568n

[20] Journel, A. and Zhang, T. (2006) The Necessity of a Multiple-Point Prior Model. Mathematical Geology, 38, 591-610. https://doi.org/10.1007/s11004-006-9031-2 